\title{
Selective Expansion of Specific T Cell Receptors in the Inflamed Colon of Crohn's Disease
}

\author{
Beena Gulwani-Akolkar, ${ }^{\star}$ Pradip N. Akolkar, ${ }^{\star}$ Arax Minassian, ${ }^{\star}$ Robert Pergolizzi, ${ }^{\ddagger}$ Mathew McKinley, ${ }^{\S}$ Gerald Mullin, ${ }^{\S}$ \\ Stanley Fisher, ${ }^{\|}$and Jack Silver* \\ $*$ Division of Molecular Medicine, Department of Medicine, ${ }^{\ddagger}$ Division of Molecular Genetics, Department of Research, ${ }^{\S}$ Division of \\ Gastroenterology, Department of Medicine, and ${ }^{\|}$Division of Gastroenterology, Department of Pediatrics, North Shore University \\ Hospital/Cornell University Medical College, Manhasset, New York 11030
}

\begin{abstract}
To identify disease-specific $T$ cell changes that occur in Crohn's disease (CD), the $\mathrm{T}$ cell receptor $\mathrm{BV}$ repertoires of lamina propria lymphocytes (LPL) isolated from both the inflamed and "disease-inactive" colons of seven CD patients were compared by the quantitative PCR and DNA sequence analysis. It was observed that the BV repertoires of LPL isolated from the disease-active and disease-inactive parts of the colon from the same individual were very different. Furthermore, nearly all of the differences occurred in $\mathrm{CD}^{+}{ }^{+} \mathrm{LPL}$, with very few differences in the $\mathrm{CD}^{+}$population of LPL. Although the pattern of BV segments that was increased in disease-active tissue relative to disease-inactive tissue was different for all seven CD patients, there were several BV segments that increased uniformly in the disease-active tissue of all seven individuals. CDR3 length analysis and DNA sequencing of these BV segments revealed that in six of the seven CD patients there was a striking degree of oligoclonality that was absent from disease-inactive tissue of the same individual. These observations suggest that at least some of the inflammation in $\mathrm{CD}$ is the result of responses by $\mathrm{CD}^{+} \mathrm{T}$ cells to specific antigens. The isolation of such inflammation-specific $\mathrm{CD}^{+} \mathrm{T}$ cells may make it possible to identify the antigens that are responsible for the inflammatory process in CD and provide a better understanding of its pathogenesis. (J. Clin. Invest. 1996. 98:13441354.) Key words: Crohn's disease $\cdot \mathrm{CD}^{+}{ }^{+}$lymphocytes $\bullet$ inflammatory bowel disease $\bullet \mathrm{T}$ cell receptor $\bullet$ lamina propria lymphocytes
\end{abstract}

\section{Introduction}

Crohn's disease $(\mathrm{CD})^{1}$ is a chronic inflammatory disease of the intestine (1) of unknown etiology. Various hypotheses have been proposed to explain the etiology and pathogenesis of CD, ranging from exposure to an infective agent to aberrant $\mathrm{T}$ cell

Address correspondence to Dr. Jack Silver, North Shore University Hospital/Cornell University Medical College, 350 Community Drive, Manhasset, NY 11030. Phone: 516-562-1113; FAX: 516-562-2866.

Received for publication 4 December 1995 and accepted in revised form 3 July 1996.

1. Abbreviations used in this paper: $\mathrm{CD}$, Crohn's disease; LPL, lamina propria lymphocytes; qPCR, quantitative PCR; TCR, T cell receptor.

J. Clin. Invest.

(c) The American Society for Clinical Investigation, Inc. 0021-9738/96/09/1344/11 \$2.00

Volume 98, Number 6, September 1996, 1344-1354 regulation (2-9). Despite this lack of basic knowledge regarding the initiating event in $\mathrm{CD}$, there is reason to believe that immunological mechanisms may explain the chronicity and relapse of CD $(10,11)$. CD is frequently accompanied by alterations in the humoral and/or cellular immune system $(12,13)$, and there is an increasing amount of evidence that at least part of the inflammation in CD is $\mathrm{T}$ cell mediated. The increased number of $\mathrm{T}$ cells expressing the activation markers 4F2, transferrin receptor, and IL-2 receptor in the intestinal lesions of $\mathrm{CD}$ suggests that $\mathrm{T}$ cells are responding to antigenic stimulation and contribute to the local inflammatory process (14-18). This is supported by other studies demonstrating higher levels of IL-2 mRNA and an increased frequency of cells secreting IL-2 and IFN- $\gamma$ in actively inflamed CD tissue compared to sites of inactive disease (19-23). Finally, recent studies suggest that $\mathrm{CD}$ is accompanied by changes in the $\mathrm{T}$ cell receptor (TCR) repertoire of LPL that occurs predominantly in the $\mathrm{CD} 4{ }^{+}$population (24).

Despite all of these studies, the nature of the stimulus that leads to activation of T cells in CD still remains undefined. Evidence for a restricted $\mathrm{T}$ cell response occurring in the lamina propria of CD patients would have important implications for the pathogenesis and treatment of the disease. Accordingly, we have analyzed the TCR repertoires of LPL from CD patients using several molecular techniques to determine whether there is any evidence of a restricted $\mathrm{T}$ cell response that would be suggestive of antigen-specific stimulation.

\section{Methods}

Patient specimens. Intestinal surgical resections were obtained from seven patients with $\mathrm{CD}$. The diagnoses of $\mathrm{CD}$ were based on clinical, endoscopic, histopathologic, and radiologic criteria (25). All specimens were from the colon and represented the first resection for all individuals. In all cases, tissue that was both grossly and histologically involved, as well as tissue that was histologically uninvolved, as determined independently by a pathologist, was used for analysis. The age, activity, and duration of disease, surgical indications, and medication of all seven patients are shown in Table I.

Cell isolation. Mononuclear cells from lamina propria were isolated by the method of Bull and Bookman (26), modified as previously described (24). Briefly, colonic mucosa was cut into small pieces and incubated with DTT, followed by EDTA treatment. The EDTA treatment was repeated two times or until crypt epithelium was no longer seen under phase microscopy. The remaining mucosal tissue was then incubated in the presence of collagenase for 6-12 h, resulting in the dissociation of the lamina propria and the release of lymphocytes. Cell viability was $>90 \%$. $\mathrm{CD}^{+}$and $\mathrm{CD}^{+}$cells were isolated using immunomagnetic beads conjugated with anti-CD4 and anti-CD $8 \mathrm{mAbs}$ as described previously, and were $>98 \%$ pure $(27,28)$.

Amplification and quantitation of $B V$-specific $R N A$ by $P C R$. BV repertoire analysis was performed by quantitative PCR (qPCR) using a modified procedure as previously described by us (28). Briefly, total cel- 
Table I. Characteristics of CD Patients

\begin{tabular}{lrllrl}
\hline & & \multicolumn{1}{c}{$\begin{array}{c}\text { Indications } \\
\text { for surgery }\end{array}$} & $\begin{array}{c}\text { Disease } \\
\text { activity }\end{array}$ & $\begin{array}{c}\text { Disease } \\
\text { duration }\end{array}$ & Medication \\
\hline & & & & $y r$ & \\
A & 14 & Partial obstruction & Moderate & 3 & None \\
B & 20 & Partial obstruction & Moderate & 5 & Prednisone \\
C & 24 & Intractable disease & Moderate & 13 & 6 MP \\
D & 19 & Intractable disease & Moderate & 2 & 5 ASA \\
E & 49 & Fistula & Moderate & 30 & 5 ASA \\
F & 15 & Partial obstruction & Mild & 2 & None \\
G & 35 & Intractable disease & Moderate & 8 & None \\
& & & & & \\
\hline
\end{tabular}

lular RNA was isolated from positively selected $\mathrm{CD} 4^{+}$and $\mathrm{CD} 8^{+}$cells with RNAzol B (Biotecx Laboratories, Houston, TX) and cDNA was synthesized using reverse $\mathrm{BC}$ and $\mathrm{AC}$ primers as described (28). BV-specific cDNA was then amplified with BV-specific primers and a ${ }^{32} \mathrm{P}$-labeled $\mathrm{BC}$ nested primer as previously described (28). As controls, a pair of $5^{\prime}$ AC forward and $3^{\prime}$ AC reverse primers was included in each reaction to specifically amplify a portion of AC RNA. The amplified products were electrophoresed on $8 \%$ polyacrylamide gels, dried, and exposed to $\mathrm{x}$-ray film. Using the autoradiograms for alignment, the amplified AC and BV bands were excised from the gel and the amount of radioactivity incorporated was determined by liquid scintillation counting. This method of quantitation is as accurate as when a phosphorimager is used for quantitation (data not shown). To correct for differences caused by pipetting errors and efficiency of amplification in each well, the cpm in each BV band was normalized to the AC band. The relative amount of each BV was expressed as a percent of the total of the cpm incorporated in all $22 \mathrm{BV}$ reactions after normalizing for $\mathrm{AC}$ $\mathrm{cpm}$. Under these conditions, the amount of radioactivity incorporated into the $\mathrm{AC}$ and $\mathrm{BV}$ bands is roughly proportional to the amount of input RNA (28). Furthermore, this modified procedure for qPCR analysis is highly reproducible and consistently gives $<15 \%$ variation when the same sample of RNA is repeatedly analyzed $(28,29)$.

Determination of oligoclonality. Assessment of oligoclonality within individual BV segments was performed as described (30). Total RNA (1-5 $\mu \mathrm{g}$ ) from selected $\mathrm{CD}^{+}{ }^{+} \mathrm{T}$ cells was converted to cDNA and amplified by qPCR as described above using BV-specific primers. An aliquot $(1-2 \mu \mathrm{l})$ of this product then served as the template for a second round of PCR using conditions that were identical to those described above, except that primer concentrations were reduced to 3 pmol per $100 \mu \mathrm{l}$ reaction mixture. After 15 cycles, 2-4 $\mu \mathrm{l}$ of the radioactive product was loaded on a standard $6 \%$ acrylamide sequencing gel. After overnight exposure to $\mathrm{x}$-ray film, BV segments of various CDR3 lengths were visualized as a series of bands $3 \mathrm{bp}$ apart and quantitated on a phosphorimager (30).

Cloning and sequencing PCR products. The PCR products of those BV segments that appeared to be oligoclonal were purified using Magic PCR preps DNA purification system (Promega, Madison, WI) and were

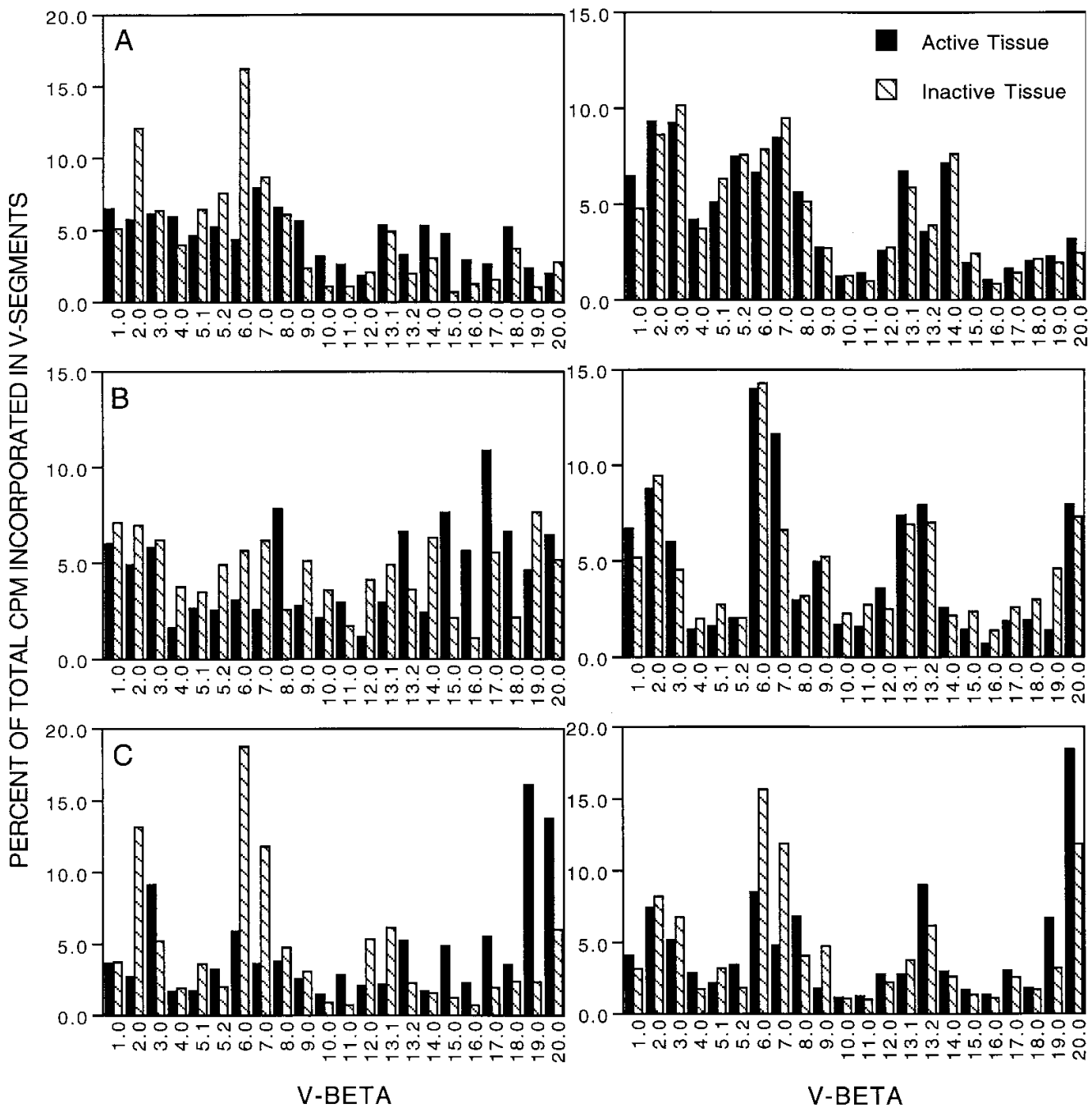

Figure 1. Comparisons of LPL TCRBV repertoires of disease-active and disease-inactive tissue by qPCR in three patients. In each case, the LPL repertoires within the same individual are compared for both $\mathrm{CD}^{+}$(left panel) and $\mathrm{CD}^{+}$(right panel) cells. 
cloned into the TA cloning vector (Novagen, Madison, WI). 30-50 colonies containing inserts were randomly selected, and the inserts were sequenced using an automated sequencer (Applied Biosystems, Inc., Foster City, CA). The sequences were analyzed using the Mac-Vector sequence analysis program (IBI-A Kodak Co., New Haven, CT).

\section{Results}

Comparisons of TCR repertoires of $L P L$ from disease-active and "disease-inactive" tissue in $C D$. Previous studies from this laboratory in which the TCR repertoires of PBL and LPL within the same individual were compared had suggested that $\mathrm{CD}$ is accompanied by an alteration in the TCR repertoire of LPL that occurs predominantly in $\mathrm{CD}^{+}$cells (24). To confirm this observation in a more definitive way, the TCR repertoires of LPL from both the disease-active and disease-inactive portions of the colons of seven CD patients were compared to each other. Because of the limited number of T cells that could be obtained from these tissues, and the fact that mAb specific for many TCR BV families are not yet available, semiquantitative PCR using BV-specific oligonucleotide was the only method by which a comprehensive analysis of the TCR repertoire for both $\mathrm{CD}^{+}$and $\mathrm{CD}^{+}$cells could be accomplished. A comparison of the $\mathrm{BV}$-specific TCR repertoires of LPL from the disease-active and adjacent disease-inactive portions of the colons of three of the seven individuals is shown in Fig. 1; the relative increase or decrease in frequency of the various BV segments in disease-active tissue vs. disease-inactive tissue is shown in schematic form for all seven patients in Table II. As can be seen, the TCR repertoires of LPL isolated from the dis- ease-active and disease-inactive portions of the colons differed extensively for all seven patients. Indeed, in all seven patients, there were many instances in which there were two-fold or greater differences in the levels of specific BV segments between the disease-active and disease-inactive portions of the colon (indicated by double and triple arrows, Table II). These extensive differences in repertoire were observed primarily in the $\mathrm{CD}^{+}$population. Especially striking were the relative increases in BV11, 15, and 17 in the disease-active tissue of all seven patients, and in BV16 in six of the seven patients; in many cases, the increases were two- and three-fold. In addition, all seven patients showed significant $(>50 \%)$ relative increases in the levels of BV13S2. In contrast, there was a striking similarity in the repertoires of $\mathrm{CD}^{+}$cells, and even when there were differences between the disease-active and diseaseinactive tissues, they did not parallel those observed in the $\mathrm{CD} 4^{+}$population.

These differences between the repertoires of LPL from disease-active and disease-inactive colonic tissue, and the restriction of these differences, for the most part, to CD4 $4^{+}$LPL cannot be attributed to either experimental error or sampling location; when a similar analysis and comparison was performed for LPL isolated from adjacent colonic sections derived from the same active lesion, no such extensive differences were observed in either the $\mathrm{CD} 4^{+}$or $\mathrm{CD} 8^{+}$populations (Table III).

Determination of oligoclonality. To determine whether the increased levels in some of the BV segments in the disease-active tissue might be caused by expansion or activation of a restricted number of $\mathrm{T}$ cells, a method that we and others have

Table II. Repertoire Comparisons of LPL Isolated from Inflamed and Normal Colon of the Same Individual for Seven Individuals

\begin{tabular}{|c|c|c|c|c|c|c|c|c|c|c|c|c|c|c|}
\hline \multirow[b]{2}{*}{ BV } & \multicolumn{7}{|c|}{ CD4 } & \multicolumn{7}{|c|}{ CD8 } \\
\hline & A & B & C & D & E & F & G & A & B & $\mathrm{C}$ & $\mathrm{D}$ & $\mathrm{E}$ & $\mathrm{F}$ & G \\
\hline 1 & - & - & - & $\downarrow$ & - & - & - & - & - & - & - & - & - & - \\
\hline 2 & $\downarrow \downarrow$ & - & $\downarrow \downarrow \downarrow$ & $\downarrow$ & - & - & 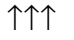 & - & - & - & - & $\downarrow$ & - & - \\
\hline 3 & - & - & $\uparrow$ & - & - & - & $\uparrow \uparrow$ & - & - & - & - & - & - & - \\
\hline 4 & - & $\downarrow \downarrow$ & - & - & - & - & - & - & - & $\uparrow$ & - & - & - & - \\
\hline 5.1 & - & - & $\downarrow \downarrow$ & - & $\uparrow \uparrow \uparrow$ & $\uparrow$ & - & - & $\downarrow$ & - & - & $\uparrow \uparrow$ & - & - \\
\hline 5.2 & - & $\downarrow$ & $\uparrow$ & - & - & - & - & - & - & $\uparrow$ & - & - & - & $\uparrow \uparrow$ \\
\hline 6 & $\downarrow \downarrow \downarrow$ & $\downarrow$ & $\downarrow \downarrow \downarrow$ & - & - & - & $\downarrow$ & - & - & $\downarrow$ & - & - & - & - \\
\hline 7 & - & $\downarrow \downarrow$ & $\downarrow \downarrow \downarrow$ & - & - & $\downarrow$ & $\downarrow$ & - & $\uparrow$ & $\downarrow \downarrow$ & - & $\downarrow$ & - & - \\
\hline 8 & - & $\uparrow \uparrow \uparrow$ & - & - & $\uparrow \uparrow$ & - & $\downarrow$ & - & - & $\uparrow$ & - & - & - & - \\
\hline 9 & $\uparrow \uparrow$ & $\downarrow$ & - & - & - & - & - & - & - & $\downarrow \downarrow$ & $\uparrow$ & - & - & - \\
\hline 10 & $\uparrow \uparrow$ & $\downarrow$ & $\uparrow$ & - & $\downarrow \downarrow \downarrow$ & $\uparrow \uparrow$ & $\uparrow \uparrow$ & - & - & - & - & - & - & $\uparrow$ \\
\hline 11 & $\uparrow \uparrow$ & $\uparrow$ & $\uparrow \uparrow \uparrow$ & $\uparrow$ & $\uparrow$ & $\uparrow \uparrow$ & $\uparrow \uparrow \uparrow$ & - & $\downarrow$ & - & - & - & - & - \\
\hline 12 & - & $\downarrow \downarrow \downarrow$ & $\downarrow \downarrow$ & - & $\uparrow \uparrow \uparrow$ & $\uparrow$ & - & - & - & - & - & - & - & - \\
\hline $13 \mathrm{~S} 1$ & - & $\downarrow$ & $\downarrow \downarrow$ & - & - & - & $\downarrow \downarrow$ & - & - & - & $\downarrow$ & - & - & - \\
\hline $13 \mathrm{~S} 2$ & $\uparrow$ & $\uparrow$ & $\uparrow \uparrow$ & $\uparrow$ & $\uparrow$ & $\uparrow$ & $\uparrow$ & - & - & - & - & $\uparrow$ & - & $\uparrow \uparrow \uparrow$ \\
\hline 14 & $\uparrow$ & $\downarrow$ & - & - & - & $\downarrow \downarrow \downarrow$ & - & - & - & - & - & - & - & $\uparrow \uparrow \uparrow$ \\
\hline 15 & $\uparrow \uparrow \uparrow$ & $\uparrow \uparrow \uparrow$ & $\uparrow \uparrow \uparrow$ & $\uparrow$ & $\uparrow$ & $\uparrow$ & $\uparrow$ & - & $\downarrow$ & - & $\uparrow$ & - & - & - \\
\hline 16 & $\uparrow \uparrow$ & $\uparrow \uparrow \uparrow$ & $\uparrow \uparrow \uparrow$ & $\uparrow$ & $\uparrow$ & $\uparrow \uparrow$ & - & - & $\downarrow$ & - & $\downarrow$ & - & - & $\uparrow$ \\
\hline 17 & $\uparrow$ & $\uparrow$ & $\uparrow \uparrow$ & $\uparrow$ & $\uparrow$ & $\uparrow \uparrow$ & $\uparrow$ & - & - & - & - & - & - & - \\
\hline 18 & - & $\uparrow \uparrow \uparrow$ & - & $\downarrow \downarrow \downarrow$ & - & - & $\downarrow \downarrow$ & - & $\downarrow$ & - & - & - & - & $\downarrow \downarrow$ \\
\hline 19 & $\uparrow \uparrow$ & $\downarrow$ & $\uparrow \uparrow \uparrow$ & - & - & $\uparrow$ & $\downarrow$ & - & $\downarrow \downarrow \downarrow$ & $\uparrow \uparrow$ & - & - & - & - \\
\hline 20 & - & - & $\uparrow \uparrow$ & $\uparrow \uparrow \uparrow$ & - & - & - & - & - & $\uparrow$ & - & - & - & $\downarrow \downarrow$ \\
\hline
\end{tabular}

$\uparrow 50-100 \%$ increase diseased over normal. $\uparrow \uparrow 100-200 \%$ increase diseased over normal. $\uparrow \uparrow \uparrow>200 \%$ increase diseased over normal. $\downarrow 50-100 \%$ decrease diseased from normal. $\downarrow \downarrow 100-200 \%$ decrease diseased from normal. $\downarrow \downarrow \downarrow>200 \%$ decrease diseased from normal. $\_<50 \%$ change. 
Table III. Repertoire Comparisons of LPL Isolated from Two Inflamed Portions of Colon of the Same Individual for Three Individuals, $A A, B B$, and $C C$

\begin{tabular}{|c|c|c|c|c|c|c|}
\hline \multicolumn{4}{|c|}{ CD4 } & \multicolumn{3}{|c|}{ CD8 } \\
\hline $\mathrm{BV}$ & $\mathrm{AA}$ & BB & $\mathrm{CC}$ & AA & BB & $\mathrm{CC}$ \\
\hline 1 & - & - & - & $\uparrow$ & $\downarrow$ & - \\
\hline 2 & - & - & - & - & - & - \\
\hline 3 & - & - & - & - & - & - \\
\hline 4 & - & - & - & $\uparrow$ & - & - \\
\hline $5 \mathrm{~S} 1$ & - & - & - & $\uparrow$ & - & - \\
\hline $5 \mathrm{~S} 2$ & - & - & - & - & - & - \\
\hline 6 & - & - & - & - & - & - \\
\hline 7 & $\downarrow$ & - & - & - & - & - \\
\hline 8 & - & - & - & - & - & - \\
\hline 9 & - & - & - & $\uparrow$ & $\uparrow$ & $\uparrow$ \\
\hline 10 & - & - & - & $\uparrow \uparrow \uparrow$ & - & - \\
\hline 11 & - & - & - & - & - & - \\
\hline 12 & - & - & - & - & - & - \\
\hline $13 \mathrm{~S} 1$ & - & - & - & - & - & - \\
\hline $13 \mathrm{~S} 2$ & - & - & - & - & - & - \\
\hline 14 & - & - & - & - & - & - \\
\hline 15 & - & - & $\downarrow$ & - & - & - \\
\hline 16 & $\uparrow \uparrow$ & - & - & $\uparrow$ & - & $\downarrow$ \\
\hline 17 & - & - & - & $\uparrow$ & $\downarrow$ & - \\
\hline 18 & - & - & - & - & - & - \\
\hline 19 & - & - & - & - & $\uparrow$ & - \\
\hline 20 & - & $\uparrow \uparrow \uparrow$ & - & - & - & - \\
\hline
\end{tabular}

$\uparrow 50-100 \%$ increase of diseased sample 1 over diseased sample $2 . \uparrow \uparrow$ $100-200 \%$ increase of diseased sample 1 over diseased sample $2 . \uparrow \uparrow \uparrow>$ $200 \%$ increase of diseased sample 1 over diseased sample $2 . \downarrow 50-100 \%$ decrease of diseased sample 1 over diseased sample $2 . \downarrow \downarrow 100-200 \%$ decrease of diseased sample 1 over diseased sample $2 .>50 \%$ change.

previously described for the rapid detection of oligoclonality was used to compare LPL from the disease-active and diseaseinactive tissues of all seven CD patients (30-32). This method, which separates PCR-amplified BV segments on the basis of their CDR3 size and is capable of detecting clonal populations at the $1-10 \%$ level, was used to analyze the joining region diversity and heterogeneity of all of the BV segments that were increased in disease-active tissue relative to disease-inactive tissue (see Methods). In all, $53 \mathrm{BV}$ segments were analyzed in this fashion (Fig. 2). Patterns that were characteristic of restricted heterogeneity and were unique to disease-active tissue were observed in at least 11 instances; in BV11 and BV16 of patient B, BV11 and BV15 of patient C, BV13S2 of patient D, BV16 of patient E, BV13S2, 15, and 17 of patient $F$, and BV2 and 16 of patient G (Fig. 2). Although additional examples of apparent oligoclonality could be observed, these appeared, in general, to be the same for both disease-active and diseaseinactive tissue (e.g., BV14 in patient A and BV20 in patient C).

In some cases, the decrease in heterogeneity and indications of oligoclonality in the disease-active tissue were very striking. For example, in patient C, LPL isolated from the disease-active colon, showed only two bands in BV11 compared to LPL isolated from disease-inactive colon which showed the characteristic six or more bands consistent with extreme heterogeneity. An even more striking example of restricted heteroge- neity was observed in BV15 of patient C, where essentially only a single intense band was observed in the disease-active tissue, suggesting a high degree of oligoclonality. In other cases, the decreases in heterogeneity were more modest (e.g., BV11 and BV16 of patient B, and BV13S2, 15, 17 of patient F). In one individual, patient $A$, there was no evidence of restricted heterogeneity unique to the disease-active tissue.

Sequences of expanded TCRBV segments. The differences in the CDR3 length patterns observed for LPL from diseaseactive and disease-inactive tissue suggested that their TCR repertoires might be different with respect to CDR3 size and sequence. Furthermore, as suggested by the limited number of bands in BV11 and BV15 in the disease-active tissue of patient $\mathrm{C}$, expansion of a limited number of $\mathrm{T}$ cells appeared to have occurred in some cases. Accordingly, BV segments that displayed restricted heterogeneity in disease-active tissue and where an apparent oligoclonal band representing at least $45 \%$ of the radioactivity in that particular BV segment was observed (see Methods) were amplified by PCR and cloned. As controls, the same BV

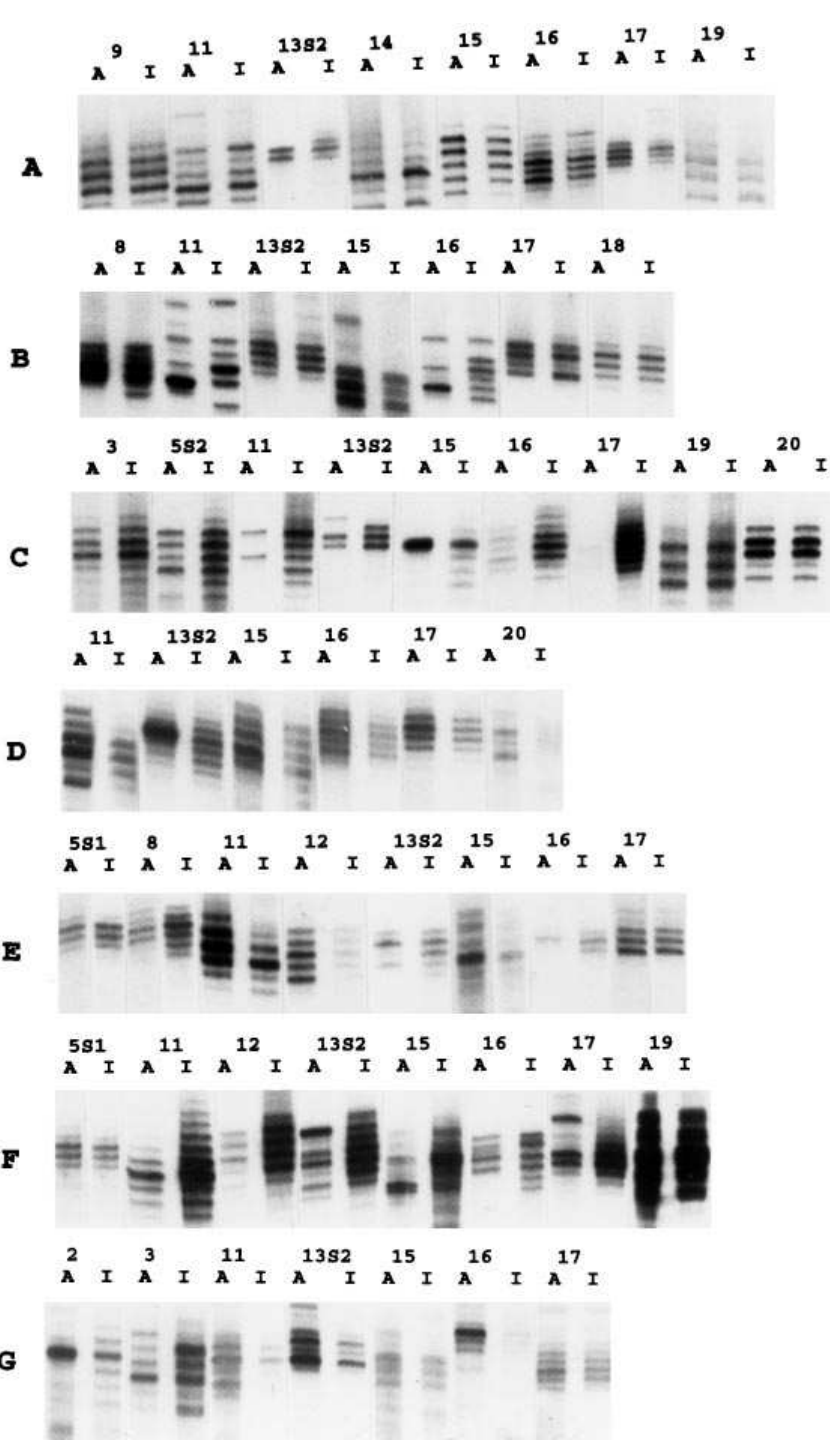

Figure 2. CDR3 length analysis of TCRBV segments from diseaseactive $(A)$ and disease-inactive $(I)$ tissue from the colons of seven patients. 
segment from the disease-inactive tissue was also amplified and cloned. Thus, for example, for patient B, PCR-amplified BV11 and BV16 segments from LPL isolated from both the disease-active and disease-inactive tissue were cloned, and a large number of clones from each were sequenced. Similarly, the BV11 and BV15 segments of patient $\mathrm{C}$ were cloned and sequenced. No BV segments were sequenced for patients $A$ and $\mathrm{F}$ because the former did not display any evidence of restricted heterogeneity by CDR3 length analysis (Fig. 2) and the latter did not display sufficient evidence of oligoclonality to warrant sequence analysis at this time. In all, of the $11 \mathrm{BV}$ segments that showed restricted heterogeneity unique to the disease-active tissue, 7 were analyzed by DNA sequencing.

The results of sequence analysis of these seven BV segments from five individuals (B, C, D, E, and $G$ ) are shown in Tables IV-VIII. This analysis revealed expansion of a limited number of TCR in all seven cases. In some cases, this expansion was very striking. For example, in patient $\mathrm{C}$, two clones represented $87 \%$ of the entire BV11 repertoire in the diseaseactive tissue, but only $2 \%$ in the "disease-inactive" tissue, and

Table IV. CDR3 Sequences in Patient B*

\begin{tabular}{|c|c|c|c|c|c|c|c|}
\hline & No. & BV Family & BV & $\mathrm{BD}$ & BJ & BJ family & $\mathrm{BC}$ \\
\hline \multicolumn{8}{|l|}{ Active } \\
\hline & $\underline{19 / 31}(61 \%)$ & 11 & CASS & GGGG & NEKLFFGSG & 1.4 & 1 \\
\hline & $3 / 31$ & 11 & CASS & ESE & NSPLHFGNG & 1.6 & 1 \\
\hline & $2 / 31$ & 11 & CASS & EDRLAGSRG & EQYFGPG & 2.7 & 2 \\
\hline & $2 / 31$ & 11 & CASS & EDGN & YEQYFGPG & 2.7 & 2 \\
\hline & $2 / 31$ & 11 & CASS & EPGTSL & DTQYFGPG & 2.3 & 2 \\
\hline & $1 / 31$ & 11 & CASS & ELSFE & ETQYFGPG & 2.5 & 2 \\
\hline & $1 / 31$ & 11 & CASS & EARTSVG & NEQFFGPG & 2.1 & 2 \\
\hline & $1 / 31$ & 11 & CASS & QGGG & NEKLFFGSG & 1.4 & 1 \\
\hline \multicolumn{8}{|c|}{ Inactive } \\
\hline & $9 / 42$ & 11 & CASS & DSTSGRG & TDTQYFGPG & 2.3 & 2 \\
\hline & $8 / 42$ & 11 & CASS & GGQN & SGNTIYFGEG & 1.3 & 1 \\
\hline & $6 / 42$ & 11 & CASS & DQTGSITSGRVD & EQFFGPG & 2.1 & 2 \\
\hline & $5 / 42(12 \%)$ & 11 & CASS & GGGG & NEKLFFGSG & 1.4 & 1 \\
\hline & $3 / 42$ & 11 & CASS & ELDRR & QETQYFGPG & 2.5 & 2 \\
\hline & $3 / 42$ & 11 & CASS & EQVL & GYTFGSG & 1.2 & 1 \\
\hline & $3 / 42$ & 11 & CASS & PGQGAD & TIYFGEG & 1.3 & 1 \\
\hline & $2 / 42$ & 11 & CASS & ESRDL & NTEAFFGQG & 1.1 & 1 \\
\hline & $2 / 42$ & 11 & CASS & LGLLAE & ETQYFGPG & 2.5 & 2 \\
\hline & $1 / 42$ & 11 & CASS & LRGPS & YEQYFGPG & 2.7 & 2 \\
\hline \multicolumn{8}{|l|}{ Active } \\
\hline & $\underline{6 / 42}(14 \%)$ & 16 & CASS & QGPR & YEQYFGPG & 2.7 & 2 \\
\hline & $\underline{6 / 42}(14 \%)$ & 16 & CASS & LPGASD & DTQYFGPG & 2.3 & 2 \\
\hline & $6 / 42(14 \%)$ & 16 & CASS & PGDSN & NSPLHFGNG & 1.6 & 1 \\
\hline & $\underline{5 / 42}(12 \%)$ & 16 & CASS & QGQ & NSPLHFGNG & 1.6 & 1 \\
\hline & $4 / 42$ & 16 & CASS & HPGLARPR & TDTQYFGPG & 2.3 & 2 \\
\hline & $4 / 42$ & 16 & CASS & QNTLRD & EQFFGPG & 2.1 & 2 \\
\hline & $3 / 42$ & 16 & CASS & PGLASVS & DTQYFGPG & 2.3 & 2 \\
\hline & $3 / 42$ & 16 & CASS & EP & NTEAFFGQG & 1.1 & 1 \\
\hline & $2 / 42$ & 16 & CASS & HQQY & TEAFFGQG & 1.1 & 1 \\
\hline & $1 / 42$ & 16 & CA & NTLGGGTEE & TQYFGPG & 2.3 & 2 \\
\hline & $1 / 42$ & 16 & CASS & QDGGY & QETQYFGPG & 2.5 & 2 \\
\hline & $1 / 42$ & 16 & CASS & QAGV & NIQYFGAG & 2.4 & 2 \\
\hline \multicolumn{8}{|c|}{ Inactive } \\
\hline & $9 / 38$ & 16 & CASS & QHRVGA & YNEQFFGPG & 2.1 & 2 \\
\hline & $9 / 38$ & 16 & CASS & QDL & NSPLHFGNG & 1.6 & 1 \\
\hline & $5 / 38$ & 16 & CASS & QNTLRD & EQFFGPG & 2.1 & 2 \\
\hline & $5 / 38$ & 16 & CASS & RQGY & EQFFGPG & 2.1 & 2 \\
\hline & $4 / 38$ & 16 & CASS & QAGLLY & YGYTFGSG & 1.2 & 1 \\
\hline & $3 / 38$ & 16 & CASS & HPGLARPR & TDTQYFGPG & 2.3 & 2 \\
\hline & $2 / 38$ & 16 & CASS & PAGV & AKNIQYFGAG & 2.4 & 2 \\
\hline & $1 / 38$ & 16 & CASS & HRTSGF & YNEQFFGPG & 2.1 & 2 \\
\hline
\end{tabular}

*Clones preferentially expanded in the disease-active tissue are underlined, and their frequency in disease-active and disease-inactive tissues are given in parentheses. 
one clone represented $92 \%$ of the entire BV15 repertoire in the disease-active tissue, but only $19 \%$ in the disease-inactive tissue (Table V). Similarly, in patient B, a single clone represented 61 vs. $12 \%$ of the entire BV11 repertoire (Table IV), in patient E, two clones represented 54 vs. $16 \%$ of the entire BV16 repertoire (Table VII), and in patient G two clones represented 53 vs. $15 \%$ of the entire BV2 repertoire for diseaseactive and disease-inactive tissue (Table VIII). In the other

Table V. CDR3 Sequences in Patient $C^{*}$

\begin{tabular}{|c|c|c|c|c|c|c|c|}
\hline & No. & BV family & BV & $\mathrm{BD}$ & BJ family & BJ & $\mathrm{BC}$ \\
\hline \multicolumn{8}{|l|}{ Active } \\
\hline & $\underline{19 / 38}(50 \%)$ & 11 & CAS & KQGLR & NSPLHFGNG & 1.6 & 1 \\
\hline & $\underline{14 / 38}(37 \%)$ & 11 & CASS & LTGLGA & NYGYTFGSG & 1.2 & 1 \\
\hline & $5 / 38$ & 11 & CASS & EPQGG & SPLHFGNG & 1.6 & 1 \\
\hline \multirow[t]{21}{*}{ Inactive } & $7 / 43$ & 11 & CASS & EDRIP & SYEQYFGPG & 2.7 & 2 \\
\hline & $6 / 43$ & 11 & CAS & RQVN & TQYFGPG & 2.3 & 2 \\
\hline & $3 / 43$ & 11 & CASS & AGQLN & SGANVLTFGAG & 2.6 & 2 \\
\hline & $3 / 43$ & 11 & CASS & EMGR & TEAFFGQG & 1.1 & 1 \\
\hline & $2 / 43$ & 11 & CASS & EIGV & EQYFGPG & 2.7 & 2 \\
\hline & $2 / 43$ & 11 & CAS & PPAGGAE & DTQYFGPG & 2.3 & 2 \\
\hline & $2 / 43$ & 11 & CASS & EEG & ETQYFGPG & 2.5 & 2 \\
\hline & $2 / 43$ & 11 & CASS & GLLGRKG & TEAFFGQG & 1.1 & 1 \\
\hline & $2 / 43$ & 11 & CASS & DPAGRKG & TEAFFGQG & 1.1 & 1 \\
\hline & $1 / 43(2 \%)$ & 11 & CASS & LTGLGA & NYGYTFGSG & 1.2 & 1 \\
\hline & $1 / 43$ & 11 & CAS & GRGAY & NSPLHFGNG & 1.6 & 1 \\
\hline & $1 / 43$ & 11 & CASS & RTGTL & NTEAFFGQG & 1.1 & 1 \\
\hline & $1 / 43$ & 11 & CASS & ESGRKA & EKLFFGSG & 1.4 & 1 \\
\hline & $1 / 43$ & 11 & CASS & EG & NQPQHFGDG & 1.5 & 1 \\
\hline & $1 / 43$ & 11 & CASS & $\mathrm{T}$ & QETQYGFPG & 2.5 & 2 \\
\hline & $1 / 43$ & 11 & CASS & DGQIV & QYFGPG & 2.7 & 2 \\
\hline & $1 / 43$ & 11 & CASS & HTGS & SYNEQFFGPG & 2.1 & 2 \\
\hline & $1 / 43$ & 11 & CASS & HTGSCC & NEQFFGPG & 2.1 & 2 \\
\hline & $1 / 43$ & 11 & CASS & PNRVLLQNRG & EQFFGPG & 2.1 & 2 \\
\hline & $1 / 43$ & 11 & CAS & QDRGKA & NTGELFFGEG & 2.2 & 2 \\
\hline & $1 / 43$ & 11 & CAS & GAGGWA & GELFFGEG & 2.2 & 2 \\
\hline \multicolumn{8}{|l|}{ Active } \\
\hline & $\underline{34 / 37}(92 \%)$ & 15 & CATS & DPHRDPSG & EQFFGPG & 2.1 & 2 \\
\hline & $3 / 37$ & 15 & CATS & DFTSGS & QETQYFGPG & 2.5 & 2 \\
\hline \multicolumn{8}{|l|}{ Inactive } \\
\hline & $6 / 31(19 \%)$ & 15 & CATS & DPHDRPSG & EQFFGPG & 2.1 & 2 \\
\hline & $3 / 31$ & 15 & CATS & DPDTGAT & NEQFFGPG & 2.1 & 2 \\
\hline & $2 / 31$ & 15 & CATS & GGARQGSG & EQFFGPG & 2.1 & 2 \\
\hline & $2 / 31$ & 15 & CATS & DPIPGVMAS & EQFFGPG & 2.1 & 2 \\
\hline & $2 / 31$ & 15 & CATS & DPSSGES & SYNEQFFGPG & 2.1 & 2 \\
\hline & $2 / 31$ & 15 & CATS & DALAGGR & DTQYFGPG & 2.3 & 2 \\
\hline & $2 / 31$ & 15 & CATS & DSTLTFR & NQPQHFGDG & 1.5 & 1 \\
\hline & $1 / 31$ & 15 & CATS & DTGTSGS & NEQFFGPG & 2.1 & 2 \\
\hline & $1 / 31$ & 15 & CATS & GPGEDI & NEQFFGPG & 2.1 & 2 \\
\hline & $1 / 31$ & 15 & CATS & DTVSD & NEQFFGPG & 2.1 & 2 \\
\hline & $1 / 31$ & 15 & CATS & EHGTSGGYAF & NEQFFGPG & 2.1 & 2 \\
\hline & $1 / 31$ & 15 & CATS & DLSPRVTGG & EQFFGPG & 2.1 & 2 \\
\hline & $1 / 31$ & 15 & CATS & DRAGGL & QETQYFGPG & 2.5 & 2 \\
\hline & $1 / 31$ & 15 & CATS & DPRPGP & STDTQYFGPG & 2.3 & 2 \\
\hline & $1 / 31$ & 15 & CATS & DRSGDGGP & TDTQYFGPG & 2.3 & 2 \\
\hline & $1 / 31$ & 15 & CATS & TGRGGG & YEQYFGPG & 2.7 & 2 \\
\hline & $1 / 31$ & 15 & CATS & DSSGVS & YEQYFGPG & 2.7 & 2 \\
\hline & $1 / 31$ & 15 & CAT & AR & NYGYTFGSG & 1.2 & 1 \\
\hline & $1 / 31$ & 15 & CAT & AAGAA & NEKLFFGSG & 1.4 & 1 \\
\hline
\end{tabular}

*Clones preferentially expanded in the disease-active tissue are underlined, and their frequency in disease-active and disease-inactive tissues are given in parentheses. 
Table VI. CDR3 Sequences in Patient D*

\begin{tabular}{|c|c|c|c|c|c|c|c|}
\hline & No. & BV family & BV & $\mathrm{BD}$ & BJ & BJ family & $\mathrm{BC}$ \\
\hline \multicolumn{8}{|l|}{ Active } \\
\hline & $\underline{6 / 40}(15 \%)$ & $13 \mathrm{~S} 2$ & CASS & SGTSG & YNEQFFGPG & 2.1 & 2 \\
\hline & $\underline{5 / 40}(13 \%)$ & $13 \mathrm{~S} 2$ & CAS & RPGTSG & YNEQFFGPG & 2.1 & 2 \\
\hline & $3 / 40$ & $13 \mathrm{~S} 2$ & CASS & PGRTGT & TEAFFGQG & 1.1 & 1 \\
\hline & $3 / 40$ & $13 \mathrm{~S} 2$ & CAS & RKGTSGH & NEQFFGPG & 2.1 & 2 \\
\hline & $2 / 40$ & $13 \mathrm{~S} 2$ & CASS & PGLAG & TGELFFGEG & 2.2 & 2 \\
\hline & $2 / 40$ & $13 \mathrm{~S} 2$ & CAS & TSSQRLV & TGELFFGEG & 2.2 & 2 \\
\hline & $2 / 40$ & $13 \mathrm{~S} 2$ & CAS & TPSRGTG & ANVLTFGAG & 2.6 & 2 \\
\hline & $2 / 40$ & $13 \mathrm{~S} 2$ & CASS & SLYV & NTEAFFGQG & 1.1 & 1 \\
\hline & $2 / 40$ & $13 \mathrm{~S} 2$ & CASS & SGLAGA & NEQFFGPG & 2.1 & 2 \\
\hline & $1 / 40$ & $13 \mathrm{~S} 2$ & CASS & AIRGP & NYGYTFGSG & 1.2 & 1 \\
\hline & $1 / 40$ & $13 \mathrm{~S} 2$ & CASS & TGSLNY & YGYTFGSG & 1.2 & 1 \\
\hline & $1 / 40$ & $13 \mathrm{~S} 2$ & CASS & YPTVG & NQPQHGGDG & 1.5 & 1 \\
\hline & $1 / 40$ & $13 \mathrm{~S} 2$ & $\mathrm{CA}$ & TDSRSTGS & PQHFGDG & 1.5 & 1 \\
\hline & $1 / 40$ & $13 \mathrm{~S} 2$ & CASS & TGTSG & YNEQFFGPG & 2.1 & 2 \\
\hline & $1 / 40$ & $13 \mathrm{~S} 2$ & CAS & RAGTKL & NEQFFGPG & 2.1 & 2 \\
\hline & $1 / 40$ & $13 \mathrm{~S} 2$ & CAS & LNQW & EQFFGPG & 2.1 & 2 \\
\hline & $1 / 40$ & $13 \mathrm{~S} 2$ & CASS & YWLAL & QETQYFGPG & 2.5 & 2 \\
\hline & $1 / 40$ & $13 \mathrm{~S} 2$ & CASS & YSWTSGGR & TQYFGPG & 2.5 & 2 \\
\hline & $1 / 40$ & $13 \mathrm{~S} 2$ & CASS & YDTA & YEQYFGPG & 2.7 & 2 \\
\hline & $1 / 40$ & $13 \mathrm{~S} 2$ & CASS & VF & YEQYFGPG & 2.7 & 2 \\
\hline & $1 / 40$ & $13 \mathrm{~S} 2$ & CASS & LPQVGQGG & EQYFGPG & 2.7 & 2 \\
\hline & $1 / 40$ & $13 \mathrm{~S} 2$ & CASS & YTRE & EQYFGPG & 2.7 & 2 \\
\hline \multicolumn{8}{|c|}{ Inactive } \\
\hline & $3 / 38$ & $13 \mathrm{~S} 2$ & CASS & YSGGH & TQYFGPG & 2.3 & 2 \\
\hline & $2 / 38$ & $13 \mathrm{~S} 2$ & CAS & NAAGF & ETQYFGPG & 2.5 & 2 \\
\hline & $2 / 38$ & $13 \mathrm{~S} 2$ & CAS & RPGTSGN & NEQFFGPG & 2.1 & 2 \\
\hline & $2 / 38$ & $13 \mathrm{~S} 2$ & CAS & PDLR & GYTFGSG & 1.2 & 2 \\
\hline & $1 / 38$ & $13 \mathrm{~S} 2$ & CASS & YRTGP & SYNEQFFGPG & 2.1 & 2 \\
\hline & $1 / 38$ & $13 \mathrm{~S} 2$ & CASS & SDQLAGGD & NEQFFGPG & 2.1 & 2 \\
\hline & $1 / 38$ & $13 \mathrm{~S} 2$ & CASS & YSRG & YNEQFFGPG & 2.1 & 2 \\
\hline & $1 / 38$ & $13 \mathrm{~S} 2$ & CASS & YTPLAGGD & NEQFFGPG & 2.1 & 2 \\
\hline & $1 / 38$ & $13 \mathrm{~S} 2$ & CASS & ARL & NEQFFGPG & 2.1 & 2 \\
\hline & $1 / 38$ & $13 \mathrm{~S} 2$ & CASS & YGLTGA & YNEQFFGPG & 2.1 & 2 \\
\hline & $1 / 38$ & $13 \mathrm{~S} 2$ & CAS & REL & NEEFFGPG & 2.1 & 2 \\
\hline & $1 / 38$ & $13 \mathrm{~S} 2$ & CAS & RKGTSGH & NEQFFGPG & 2.1 & 2 \\
\hline & $1 / 38$ & $13 \mathrm{~S} 2$ & CAS & YFGQESL & FFGPG & 2.1 & 2 \\
\hline & $1 / 38$ & $13 \mathrm{~S} 2$ & CAS & $\mathrm{T}$ & SYNEQFFGPG & 2.1 & 2 \\
\hline & $1 / 38$ & $13 \mathrm{~S} 2$ & CAS & TAPKKGPS & SYNEQFFGPG & 2.1 & 2 \\
\hline & $1 / 38$ & $13 \mathrm{~S} 2$ & CA & TAGTGT & EQFFGPG & 2.1 & 2 \\
\hline & $1 / 38$ & $13 \mathrm{~S} 2$ & CASS & YYFAYT & STDTQYFGPG & 2.3 & 2 \\
\hline & $1 / 38$ & $13 \mathrm{~S} 2$ & CASS & YSTR & DTQYFGPG & 2.3 & 2 \\
\hline & $1 / 38$ & $13 \mathrm{~S} 2$ & CASS & YREW & TDTQYFGPG & 2.3 & 2 \\
\hline & $1 / 38$ & $13 \mathrm{~S} 2$ & CASS & SNAGLAGA & TDTQYFGPG & 2.3 & 2 \\
\hline & $1 / 38$ & $13 \mathrm{~S} 2$ & CASS & YPIAG & AKNIQYFGAG & 2.4 & 2 \\
\hline & $1 / 38$ & $13 \mathrm{~S} 2$ & CASS & RPAG & TQYFGPG & 2.5 & 2 \\
\hline & $1 / 38$ & $13 \mathrm{~S} 2$ & CAS & KKHWDRDSA & GYTFGSG & 1.2 & 1 \\
\hline & $1 / 38$ & $13 \mathrm{~S} 2$ & CASS & GQSI & NQPQHFGDG & 1.5 & 1 \\
\hline & $1 / 38$ & $13 \mathrm{~S} 2$ & CASS & YRDRYY & QPQHFGDG & 1.5 & 1 \\
\hline & $1 / 38$ & $13 \mathrm{~S} 2$ & CASS & $\mathrm{RM}$ & NTEAFFGQG & 1.1 & 1 \\
\hline & $1 / 38$ & $13 \mathrm{~S} 2$ & CAS & RTGV & NTEAFFGQG & 1.1 & 1 \\
\hline & $1 / 38$ & $13 \mathrm{~S} 2$ & CAS & RVPPQDM & NTEAFFGQG & 1.1 & 1 \\
\hline & $1 / 38$ & $13 \mathrm{~S} 2$ & CAS & NPLDTRDL & NTEAFFGQG & 1.1 & 1 \\
\hline & $1 / 38$ & $13 \mathrm{~S} 2$ & CAS & RTDH & YEQYFGPG & 2.7 & 2 \\
\hline & $1 / 38$ & $13 \mathrm{~S} 2$ & CAS & RESGGAGRD & EQYFGPG & 2.7 & 2 \\
\hline & $1 / 38$ & $13 \mathrm{~S} 2$ & CAS & YSIGGTS & YEQYFGPG & 2.7 & 2 \\
\hline & $1 / 38$ & $13 \mathrm{~S} 2$ & CAS & RKPTGAS & YEQYFGPG & 2.7 & 2 \\
\hline
\end{tabular}

*Clones preferentially expanded in the disease-active tissue are underlined, and their frequency in disease-active and disease-inactive tissues are given in parentheses. 
two cases (BV16 in patient B and BV13S2 in patient D), evidence of expansion was less striking although the dominant clones present in the disease-active tissue were completely absent from the disease-inactive tissue. Thus, in all seven cases representing five different patients, there was a clear difference in the distribution of TCR in disease-active and diseaseinactive tissue, as well as evidence of preferential expansion of a limited number of TCR in the disease-active tissue.

\section{Discussion}

Previous studies from this laboratory in which the TCR repertoires of LPL and PBL within the same individual were com- pared for both $\mathrm{CD}$ and control groups had suggested that in $\mathrm{CD}$ there is a dramatic change in the TCR repertoire of $\mathrm{CD} 4^{+}$ LPL. To confirm this observation and to determine whether the observed changes in the repertoire displayed restricted heterogeneity indicative of an antigen-specific response, the TCR repertoires of LPL isolated from both disease-active and disease-inactive colonic tissue of seven CD patients were compared. Disease-inactive tissue was independently defined by a pathologist as tissue that showed no gross or histological evidence of inflammation. By comparing disease-active and disease-inactive tissue within the same individual, we could eliminate the possibility that any observed differences in repertoire were caused by individual genetic differences or mode of ther-

Table VII. CDR3 Sequences in Patient E*

\begin{tabular}{|c|c|c|c|c|c|c|c|}
\hline & No. & BV family & BV & $\mathrm{BD}$ & BJ & BJ family & $\mathrm{BC}$ \\
\hline \multicolumn{8}{|l|}{ Active } \\
\hline & $\underline{11 / 33}(33 \%)$ & 16 & CASS & KRDRMK & TQYFGPG & 2.5 & 2 \\
\hline & $7 / 33(21 \%)$ & 16 & CAS & RKIGGRH & YGYTFGSG & 1.2 & 1 \\
\hline & $\overline{3 / 33}$ & 16 & CASS & QDPGRM & EKLFFGSG & 1.4 & 1 \\
\hline & $2 / 33$ & 16 & CASS & QAIGDT & GNTIYFGEG & 1.3 & 1 \\
\hline & $1 / 33$ & 16 & CASS & PQRRGY & QETQYFGPG & 2.5 & 2 \\
\hline & $1 / 33$ & 16 & CASS & RTVS & YGYTFGSG & 1.2 & 1 \\
\hline & $1 / 33$ & 16 & CASS & QVSSN & NEQFFGPG & 2.1 & 2 \\
\hline & $1 / 33$ & 16 & CASS & QMSGTG & EQFFGPG & 2.1 & 2 \\
\hline & $1 / 33$ & 16 & CASS & RQY & EQFFGPG & 2.1 & 2 \\
\hline & $1 / 33$ & 16 & CAS & RQNPHS & GELFFGEG & 2.2 & 2 \\
\hline & $1 / 33$ & 16 & CASS & RRLAG & TDTQYFGPG & 2.3 & 2 \\
\hline & $1 / 33$ & 16 & CAS & RQHFGQGH & SYEQYFGPG & 2.7 & 2 \\
\hline & $1 / 33$ & 16 & CASS & PELEGA & PLHFGNG & 1.6 & 1 \\
\hline & $1 / 33$ & 16 & CASS & LNGQAAG & QPQHFGDG & 1.5 & 1 \\
\hline \multicolumn{8}{|c|}{ Inactive } \\
\hline & $3 / 31(10 \%)$ & 16 & CASS & KRDRMK & TQYFGPG & 2.5 & 2 \\
\hline & $3 / 31$ & 16 & CASS & QLTSY & YNEQFFGPG & 2.1 & 2 \\
\hline & $2 / 31$ & 16 & CASS & QFLSGGR & NEQFFGPG & 2.1 & 2 \\
\hline & $2 / 31(6 \%)$ & 16 & CAS & RKIGGRH & YGYTFGSG & 1.2 & 1 \\
\hline & $2 / 31$ & 16 & CASS & RTSGTS & TDTQYFGPG & 2.3 & 2 \\
\hline & $1 / 31$ & 16 & CASS & QDPGRM & EKLFFGSG & 1.4 & 1 \\
\hline & $1 / 31$ & 16 & CASS & QDIGPG & EKLFFGSG & 1.4 & 1 \\
\hline & $1 / 31$ & 16 & CASS & QATGSSALA & TNEKLFFGSG & 1.4 & 1 \\
\hline & $1 / 31$ & 16 & CASS & PRVNS & NEKLFFGSG & 1.4 & 1 \\
\hline & $1 / 31$ & 16 & CAS & RGYSGS & YGYTFGSG & 1.2 & 1 \\
\hline & $1 / 31$ & 16 & CAS & PAAKNV & YGYTFGSG & 1.2 & 1 \\
\hline & $1 / 31$ & 16 & CASS & QLLAG & QETQYFGPG & 2.5 & 2 \\
\hline & $1 / 31$ & 16 & CASS & PRDKMN & TQYFGPG & 2.5 & 2 \\
\hline & $1 / 31$ & 16 & CASS & QIGVR & YNEQFFGPG & 2.1 & 2 \\
\hline & $1 / 31$ & 16 & CASS & QGRDD & EQFFGPG & 2.1 & 2 \\
\hline & $1 / 31$ & 16 & CASS & QVW & NTEAFFGQG & 1.1 & 1 \\
\hline & $1 / 31$ & 16 & CASS & QVEGQG & AFFGQG & 1.1 & 1 \\
\hline & $1 / 31$ & 16 & CASS & QQV & QGELFFGEG & 2.2 & 2 \\
\hline & $1 / 31$ & 16 & CASS & $\mathrm{RDA}$ & GELFFGEG & 2.2 & 2 \\
\hline & $1 / 31$ & 16 & CASS & QGFRRDA & GELFFGEG & 2.2 & 2 \\
\hline & $1 / 31$ & 16 & CASS & FCYR & STDTQYFGPG & 2.3 & 2 \\
\hline & $1 / 31$ & 16 & CASS & LLAGF & TDTQYFGPG & 2.3 & 2 \\
\hline & $1 / 31$ & 16 & CASS & QVTIR & DTQYFGPG & 2.3 & 2 \\
\hline & $1 / 31$ & 16 & CASS & LTRGV & EQYFGPG & 2.7 & 2 \\
\hline
\end{tabular}

*Clones preferentially expanded in the disease-active tissue are underlined, and their frequency in disease-active and disease-inactive tissues are given in parentheses. 
apy. Furthermore, since LPL from disease-active and diseaseinactive tissues were derived from adjacent surgical specimens, we minimized repertoire differences that might be caused by cellular compartmentalization, such as those we have previously documented for $\mathrm{T}$ cells from peripheral blood and the lamina propria compartment (24). This was confirmed by our comparison of LPL isolated from two adjacent segments of disease-active tissue of several $\mathrm{CD}$ patients, where we observed very few differences in CDR3 length profiles (data not shown) and repertoire (Table III).

When the repertoires of LPL from disease-active and disease-inactive tissue were compared within the same individual, we observed major differences in the $\mathrm{CD} 4^{+}$population for all seven CD patients (Fig. 1 and Table II). In contrast, the repertoires of $\mathrm{CD}^{+}$LPL from the disease-active and disease-inactive tissue of the same individual were strikingly similar. These observations confirm our previous conclusion that $\mathrm{CD}$ is accompanied by repertoire changes that occur predominantly in $\mathrm{CD} 4^{+} \mathrm{LPL}$ (24). These studies also reveal that although each patient is characterized by a unique pattern of repertoire differences, there are several BV segments that uniformly increase in the disease-active tissue of all seven CD patients relative to disease-inactive tissue. For all seven CD patients, there were significant increases ( $>50 \%)$ in the levels of BV11, 13S2, 15, and 17 (Table II). In addition, BV16 increased in six of the seven patients. In many of these cases, the increases were two- or threefold (Table II).

The increases in the relative levels of RNA encoding several different BV segments in the disease-active tissue relative to disease-inactive tissue suggested that there was a preferential activation and/or proliferation of $\mathrm{T}$ cells expressing these BV segments. To determine whether this preferential activation might be restricted to $\mathrm{T}$ cells expressing a small number of different receptors (i.e., oligoclonal), we used an assay that we have previously used to detect oligoclonality in PBL and LPL $(30,31)$. This analysis revealed evidence of oligoclonality that was unique to the disease-active tissue of six of the seven patients; only in patient A was there no evidence of oligoclonality by this assay (Fig. 2). Sequence analysis of BV segments that displayed restricted heterogeneity patterns unique to the disease-active tissue confirmed the CDR3 length analysis data;

Table VIII. CDR3 Sequences in Patient $G^{*}$

\begin{tabular}{|c|c|c|c|c|c|c|c|}
\hline & No. & BV family & $\mathrm{BV}$ & $\mathrm{BD}$ & BJ & BJ family & $\mathrm{BC}$ \\
\hline \multicolumn{8}{|l|}{ Active } \\
\hline & $13 / 34(38 \%)$ & 2 & $\mathrm{CS}$ & ARGD & SNQPQHFGDG & 1.5 & 1 \\
\hline & $\underline{5 / 34}(15 \%)$ & 2 & $\mathrm{CS}$ & ARNPRAGG & TDTQYFGPG & 2.3 & 2 \\
\hline & $\overline{4 / 34}$ & 2 & CAS & RKIGGRH & YGYTFGSG & 1.2 & 1 \\
\hline & $2 / 34$ & 2 & CS & ARDASGTV & YNEQFFGPG & 2.1 & 2 \\
\hline & $1 / 34$ & 2 & $\mathrm{CS}$ & ALFRTGPG & QPQHFGDG & 1.5 & 1 \\
\hline & $1 / 34$ & 2 & $\mathrm{CS}$ & ANTGPA & QPQHFGDG & 1.5 & 1 \\
\hline & $1 / 34$ & 2 & CS & ARC & DTQYFGPG & 2.3 & 2 \\
\hline & $1 / 34$ & 2 & $\mathrm{CS}$ & ARDAGGAK & DTQYFGPG & 2.3 & 2 \\
\hline & $1 / 34$ & 2 & $\mathrm{CS}$ & ASRLAGGF & YNEQFFGPG & 2.1 & 2 \\
\hline & $1 / 34$ & 2 & $\mathrm{CS}$ & ARAGPGY & EQYFGPG & 2.7 & 2 \\
\hline & $1 / 34$ & 2 & $\mathrm{CS}$ & ATLP & QETQYFGPG & 2.5 & 2 \\
\hline & $1 / 34$ & 2 & CS & GGV & QETQYFGPG & 2.5 & 2 \\
\hline & $1 / 34$ & 2 & $\mathrm{CS}$ & ARTAG & GNTIYFGEG & 1.3 & 1 \\
\hline & $1 / 34$ & 2 & $\mathrm{CS}$ & ASPTGR & GNTIYFGEG & 1.3 & 1 \\
\hline \multicolumn{8}{|c|}{ Inactive } \\
\hline & $4 / 27(15 \%)$ & 2 & $\mathrm{CS}$ & ARGD & SNQPQHFGDG & 1.5 & 1 \\
\hline & $4 / 27$ & 2 & $\mathrm{CS}$ & APTGTA & NYGYTFGSG & 1.2 & 1 \\
\hline & $3 / 27$ & 2 & CS & ARAP & QDPQHFGDG & 1.5 & 1 \\
\hline & $2 / 27$ & 2 & $\mathrm{CS}$ & ASGDT & QYFGPG & 2.7 & 2 \\
\hline & $2 / 27$ & 2 & CS & ARAKRTGK & NEKLFFGSG & 1.4 & 1 \\
\hline & $2 / 27$ & 2 & $\mathrm{CS}$ & ARDTGF & SGNTIYFGEG & 1.3 & 1 \\
\hline & $1 / 27$ & 2 & CS & GGV & QETQYFGPG & 2.5 & 2 \\
\hline & $1 / 27$ & 2 & CAS & RKIGGRH & YGYTFGSG & 1.2 & 1 \\
\hline & $1 / 27$ & 2 & $\mathrm{CS}$ & ARDPGAT & NEKLFFGSG & 1.4 & 1 \\
\hline & $1 / 27$ & 2 & $\mathrm{CS}$ & ARGRYR & EQYFGPG & 2.7 & 2 \\
\hline & $1 / 27$ & 2 & $\mathrm{CS}$ & AKRLASS & YNEQFFGPG & 2.1 & 2 \\
\hline & $1 / 27$ & 2 & CAS & ASLP & YGYTFGSG & 1.2 & 1 \\
\hline & $1 / 27$ & 2 & CS & ARQRGGEG & SDTQYFGPG & 2.3 & 2 \\
\hline & $1 / 27$ & 2 & $\mathrm{CS}$ & ASIKRG & TDTQYFGPG & 2.3 & 2 \\
\hline & $1 / 27$ & 2 & CS & AGGGRG & GYTFGSG & 1.2 & 1 \\
\hline & $1 / 27$ & 2 & $\mathrm{CS}$ & ASQGAR & SDTQYFGPG & 2.3 & 2 \\
\hline
\end{tabular}

*Clones preferentially expanded in the disease-active tissue are underlined, and their frequency in disease-active and disease-inactive tissues are given in parentheses. 
the TCR sequences present in disease-active tissue were distinct from those present in disease-inactive tissue, and there was evidence of selective expansion of a small number of $\mathrm{T}$ cells (Tables IV-VIII). In a few cases, TCR that were greatly expanded in the disease-active tissue were also observed in the disease-inactive tissue, although at a much lower frequency, suggesting that even in disease-inactive tissue there is already a partial expansion of $\mathrm{T}$ cells expressing these receptors. It is very likely that continued activation and expansion of $\mathrm{T}$ cells bearing these receptors are responsible for much of the inflammation in the disease-active tissue, although it is not clear why these $\mathrm{T}$ cells should suddenly become activated.

One possibility, which is suggested by the large increases in the levels of several BV segments in disease-active tissue relative to disease-inactive tissue, is activation by one or more "superantigens" that are known to activate polyclonal $\mathrm{T}$ cells in a $\mathrm{BV}$-specific fashion $(33,34)$. Although the polyclonality of these BV segments of individual A is consistent with a superantigen-like response, the extreme oligoclonality observed in some of the other patients argue against a superantigen-like response. It may be that both superantigens and antigen-specific responses contribute to the inflammation observed in CD. Alternatively, there may be several different etiologies for CD. Such a scenario, in which there are different etiologies leading to the same gross manifestations, have been proposed for other autoimmune diseases (35-37), and are supported by animal models of inflammatory bowel disease where different defects in or insults to the immune system lead to diseases with grossly similar characteristics (38-45). Further analysis of the inflammatory response in additional CD patients may allow us to distinguish between these various models and provide a better understanding of the etiology of CD.

In summary, our data suggest that at least in some CD patients there is evidence of a highly restricted $\mathrm{T}$ cell response. It remains to be determined whether these $\mathrm{T}$ cells play a primary role in initiating the disease process or are secondary to the initial event. Nevertheless, our identification of selectively expanded $\mathrm{T}$ cells suggests that it may be possible to identify the antigen(s) responsible for much of the inflammation in CD, and opens the door to the possibility of therapy aimed at tolerizing the patient to these antigens.

\section{Acknowledgments}

The authors wish to thank Colleen Millan for her help with DNA sequencing.

This work was supported by National Institutes of Health grants AI22005 and AR40982 to J. Silver. This is publication No. 59 from the Division of Molecular Medicine.

\section{References}

1. MacDermott, R.P., and W.F. Stenson. 1988. Alterations of the immune system in ulcerative colitis and Crohn's disease. Adv. Immunol. 42:285-326.

2. Kirsner, J.B., and R.G. Shorter. 1982. Recent developments in nonspecific inflammatory bowel disease. N. Engl. J. Med. 306:837-848.

3. Fiocchi, C. 1986. Intestinal mucosal lmphocytes: a new approach to pathogenesis of inflammatory bowel disease. In Inflammatory Bowel Diseases. D. Rachmilewitz, editor. Martinus Nijhoff Publishers, Dordrecht, The Netherlands. p. 73-85.

4. Strober, W., and S.P. James. 1986. The immunologic basis of inflammatory bowel disease. J. Clin. Immunol. 6:415-432.

5. James, S.P., W. Strober, T.C. Quinn, and S.H. Danovitch. 1987. New concepts of pathogenesis and current approaches to treatment. Dig. Dis. Sci. 32: 1297-1310.
6. Walvoort, H.C., and A.S. Pena. 1987. Crohns disease: entity and aetiopathogenic concepts. J. Clin. Nutr. Gastroenterol. s2:194-200.

7. Mayer, L., and D. Eisenhardt. 1990. Lack of induction of suppressor T cells by intestinal epithelial cells from patients with inflammatory bowel disease. J. Clin. Invest. 86:1255-1260.

8. Posnett, D.N., I. Schmelkin, D.A. Burton, A. August, H. McGrath, and L. Mayer. 1990. T cell antigen receptor V gene usage. Increases in $\mathrm{V} \beta 8^{+} \mathrm{T}$ cells in Crohn's disease. J. Clin. Invest. 85:1770-1776.

9. Strober, W., and R.O. Ehrhardt. 1993. Chronic intestinal inflammation: an unexpected outcome in cytokine or T cell receptor mutant mice. Cell. 75: 203-205.

10. Powrie, F. 1995. T cells in inflammatory disease: protective and pathogenic roles. Immunity. 3:171-174.

11. Lowes, J.R., and D.P. Jewell. 1990. The immunology of inflammatory bowel disease. Spingers Sem. Immunopathol. 12:251-268.

12. Deusch, K., and K. Reich. 1992. Immunological aspects of inflammatory bowel disease. Endoscopy. 24:568-577.

13. Fiochi, C. 1990. Immune events associated with inflammatory bowel disease. Scand. J. Gastroenterol. 25:4-12.

14. James, S.P., C. Fiochi, A.S. Graeff, and W. Strober.1985. Immunoregulatory function of lamina propria T cells in Crohn's disease. Gastroenterology. 85:1143-1150

15. Raedler, A., S. Fraenkel, G. Klose, K. Seyfarth, and H.G. Thiele. 1985. Involvement of the immune system in the pathogenesis of Crohn's disease. Expression of the T9 antigen on peripheral immunocytes correlates with the severity of the disease. Gastroenterology. 88:978-983.

16. Raedler, A., S. Fraenkel, G. Klose, and H.G. Thiele. 1985. Elevated numbers of peripheral $\mathrm{T}$ cells in inflammatory bowel disease displaying the T9 antigen and Fc receptors. Clin. Exp. Immunol. 60:518-524.

17. Schreiber, S., R.P. MacDermott, A. Raedler, R. Pinnau, M.J. Bertovich, and G.S. Nash. 1991. Increased activation of isolated intestinal lamina propia mononuclear cells in inflammatory bowel disease. Gastroenterology. 101:1020 1030.

18. Pallone, F., S. Fais, O. Squarcia, L. Biancone, P. Pozzill, and M. Boirivant. 1987. Activation of peripheral blood and lamina propia lymphocytes in Crohn's disease. In vivo state of activation and in vitro response to stimulation as defined by the expression of early activation antigens. Gut. 28:745-753.

19. Konttinen, Y.T., V. Bergroth, D. Nordstrom, M. Segerberg-Konttinen, K. Seppala, and M. Salaspur. 1987. Lymphocyte activation in vivo in the intestinal mucosa of patients with Crohn's disease. J. Clin. Lab. Immunol. 22:59-63.

20. Mullin, G.E, A. Lazenby, M. Harris, T. Bayless, and S.P. James. 1992. Increased interleukin-2 messenger RNA in the intestinal mucosal lesions of Crohn's disease but not ulcerative colitis. Gastroenterology. 102:1620-1627.

21. Breese, E., C.P. Braegger, C.J. Corrigan, J.A. Walker-Smith, and T.T MacDonald. 1993. Interleukin 2 and interferon-gamma secreting T cells in normal and diseased intestinal mucosa. Immunology. 78:127-131.

22. Mullin, G.E., Z.R. Maycon, A. Sampat, F.R. Vezza, L.B. Elwert-Braun, R. Duchmann, G. Weissman, S. Katz, M.M. McKinley, S.P. James, and S.E. Fisher. 1994. Intestinal mucosal lymphokine production in Crohn's disease has a Th1 profile. Gastroenterology. 104:A705.

23. Choy, M.Y., J.A. Walker-Smith, C.B. Williams, and T.T. MacDonald. 1990. Differential expression of CD25 (interleukin-2 receptor) on lamina propria T cells and macrophages in the intestinal lesions in Crohn's disease and ulcerative colitis. Gut. 31:1365-1370.

24. Gulwani-Akolkar, B., P.N. Akolkar, M. McKinley. S.E. Fisher, and J. Silver. 1995. Crohn'sdisease is characterised by major alterations in the T cell receptor $\mathrm{V} \beta$ repertoire of $\mathrm{CD} 4^{+}$, but not $\mathrm{CD} 8^{+}$, lamina propia lymphocytes. Clin. Immunol. Immunopathol. 77:95-105.

25. Yardley, J.H., and M. Donowitz. 1977. Colo-rectal biopsy in inflammatory bowel disease. In The Gastrointestinal Tract. J.H. Morrison, B.C. Morson, and M.R. Abell, editors. Williams and Wilkins, Baltimore, MD. p. 50-94.

26. Bull, D.M., and M.A. Bookman. 1977. Isolation and functional characterization of human intestinal mucosal lymphoid cells. J. Clin. Invest. 59:966974

27. Gulwani-Akolkar, B., D.N. Posnett, C.H. Janson, J. Grunewald, H. Wigzell, P. Akolkar, P. Gregersen, and J. Silver. 1991. T cell receptor V-segment frequencies in peripheral blood $\mathrm{T}$ cells correlate with human leukocyte antigen type. J. Exp. Med. 174:1139-1146.

28. Akolkar, P.N., B. Gulwani-Akolkar, R. Pergolizzi, R.D. Bigler, and J. Silver. 1993. The influence of HLA genes on TCR V-segment frequencies and expression levels in peripheral blood lymphocytes. J. Immunol. 150:4761-4773.

29. Akolkar, P.N., B. Gulwani-Akolkar, and J. Silver. 1996. Methods for the analysis of the human $\mathrm{T}$ cell receptor (TCR) repertoire in health and disease. In CRC Handbook of Human Immunology. CRC Press, Boca Raton, FL. In press.

30. Akolkar, P.N., B. Gulwani-Akolkar, M. McKinley, S.E. Fisher, and J. Silver. 1995. Comparisons of T cell receptor (TCR) V $\beta$ repertoire of lamina propia and peripheral blood lymphocytes. Clin. Immunol. Immunopathol. 76:155-163.

31. Hingorani, R., I.H. Choi, P. Akolkar, B. Gulwani-Akolkar, R. Pergolizzi, J. Silver, and P.K. Gregersen. 1993. Clonal expansion of $\mathrm{CD}^{+} \mathrm{CD}^{+} \mathrm{RO}^{+} \mathrm{T}$ cells in normal human subjects. J. Immunol. 151:5762-5769.

32. Blumberg, R.S., C.E. Yockey, G.G. Gross, E.C. Ebert, and S.P. Balk. 1993. Human intestinal intraepithelial lymphocytes are derived from a limited number of 
T cell clones that utilize multiple V $\beta$ receptor genes. J. Immunol. 150:5144-5153.

33. Herman, A., J.W. Kappler, P. Marrack, and A.M. Pullen. 1991. Superantigens: mechanism of T cell stimulation and role in immune responses. Annu. Rev. Immunol. 9:7745-7772.

34. Drake, C.G., and B.L. Kotzin 1992. Superantigens: biology, immunology, and potential role in disease. J. Clin. Immunol. 12:149-162.

35. Weyand, C.M., X. Congping, and J.J. Goronzy. 1992. Homozygosity for the HLA-DRB1 allele selects for extraarticular manifestations in rheumatoid arthritis. J. Clin. Invest. 89:2033-2039.

36. Weyand, C.M., K.C. Hicok, D.L. Conn, and J.J. Goronzy. 1992. The influence of HLA-DRB1 genes on disease severity in rheumatoid arthritis. Ann. Int. Med. I17:801-806.

37. Nepom, G.T. 1995. Class II antigens and disease susceptibility. Annu Rev. Med. 46:17-25.

38. Hammer, R.E., S.D. Maika, J.A. Richardson, J.P. Tang, and J.D. Taurog. 1990. Spontaneous inflammatory disease in transgenic rats expressing HLA-B27 and human $\beta-2 \mathrm{~m}$ : and animal model of HLA-B27-asssociated human disorders. Cell. 63:1099-1112.

39. Kuhn, R., J. Lohler, D. Rennick, K. Rajewsky, and W. Miller. 1993. Interleukin-10 deficient mice develop chronic colitis. Cell. 75:263-274.
40. Kulkarni, A.B., and S. Karlsson. 1993. Transforming growth factor-beta 1 knockout mice. A mutation in one cytokine gene causes a dramatic inflammatory disease. Am. J. Pathol. 143:3-9.

41. Morrissey, P.J., K. Charreir, S. Braddy, D. Liggit, and J.D. Watson. 1993. $\mathrm{CD}^{+} \mathrm{T}$ cells that express high levels of CD45RB induce wasting disease when transferred into congenic severe combined immunodeficient mice: disease development is prevented by cotransfer of purified $\mathrm{CD}^{+}{ }^{+}$T cells. J. Exp. Med. 178:237-244.

42. Rudolph, U., M.J. Finegold, S.S. Rich, G.R. Harriman, Y. Srinivasan, P. Brabet, G. Boulay, A. Bradley, and L. Birnbaumer. 1995. Ulcerative colitis and adenocarcinoma of the colon in Gai2-deficient mice. Nature Genet. 10:143-150.

43. Mombaerts, P., E. Mizoguchi, M.J. Grusby, L.H. Glimcher, A.K. Bhan, and S. Tonegawa. 1993. Spontaneous development of inflammatory disease in T cell receptor mutant mice. Cell. 75:274-282.

44. Sadlack, B., H. Merz, H. Schorle, A. Schimpi A. Feller, and I. Horak. 1993. Ulcerative colitis-like disease in mice with a disrupted interleukin-2 gene. Cell. 75:253-261.

45. Hollander, G.A., S.J. Simpson, E. Mizoguchi, A. Nichogiannopoulou, J. She, J.C. Guttierrez-Ramos, A.K. Bahn, S.J. Burakoff, B. Wang, and C. Terhorst. 1995. Severe colitis in mice with aberrant thymic selection. Immunity. 3:27-38. 